\title{
鸡MC4R基因的SNPs及其与屠体性状 的相关研究 ${ }^{*}$
}

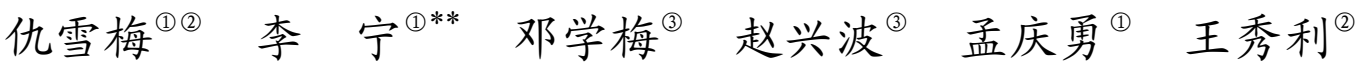

(1) 中国农业大学农业生物技术国家重点实验室，北京 100094; (2) 大连水产学院生命科学与技术学院，大连 116023;

(3) 中国农业大学动物科技学院，北京 100094)

\begin{abstract}
摘要黑素皮质素受体(MC4R, melanocortin-4 receptor)基因的突变与猪、鼠和人等的食欲、肥 胖、生长等性状有关, 而鸡 $M C 4 R$ 基因的功能却知之甚少. 利用 PCR-SSCP(single strand conformation polymorphism)和 DNA测序的方法，对资源家系 $\mathrm{F}_{2}$ 代鸡群 $M C 4 R$ 基因多态性进 行了分析, 发现存在 4 个单核苷酸多态(SNPs, single nucleotide polymorphisms)位点. 其中, 在MC4R 基因 $5^{\prime}$ 调控区-524 nt发生了碱基的转换突变 $(\mathrm{C} \rightarrow \mathrm{T})$, 导致突变型基因比野生型基因多 了一个NF-E2 和一个cap转录因子结合位点; 在MC4R编码区 (61 nt)发生了碱基的错义突变 $(\mathrm{G} \rightarrow \mathrm{A})$, 导致此处蛋白质的氨基酸由甘氨酸变为精氨酸; 在 $M C 4 R$ 编码区 315 和 $336 \mathrm{nt}$ 发生了碱基的颠换 突变 $(\mathrm{G} \rightarrow \mathrm{T})$ 和转换突变 $(\mathrm{C} \rightarrow \mathrm{T})$, 这两个突变为同义突变. 通过最小二乘分析 SNPs 与屠体性状的 关系, 结果是突变的 $\mathrm{BB}, \mathrm{DD}$ 和 $\mathrm{FF}$ 等基因型与鸡的体重、全净膛重(或半净膛重)、腿肉重等存在显 著 $(P<0.05)$ 或极显著 $(P<0.01)$ 的关系, 但与腹脂重不显著. 结果表明, $M C 4 R$ 基因可以作为影响和 控制鸡体重、生长等屠体性状的主要候选基因.
\end{abstract}

\section{关键词黑素皮质素受体 4 SNPs 鸡 屠体性状}

黑素皮质素受体 4(MC4R, melanocortin-4 receptor) 是下丘脑腹内侧核 $(\mathrm{VMH})$ 分泌的一类肽类物质 ${ }^{[1]}$, 为 黑素皮质素家族 5 个成员之一. MC4R属于 $\mathrm{G}$-蛋白耦 联受体(GPCRS, G-protein coupled receptors)超级家族, 为跨膜神经受体 ${ }^{[2,3]}$. MC4R 可与脑部分泌的天然内源
配体 $\alpha$-促黑激素( $\alpha$-MSH, alpha melanocyte-stimulating hormone)结合, 抑制体重的增加 ${ }^{[4]}$. 在哺乳动物中, MC4R 具有介导Leptin蛋白的功能, 是一个调节能量 平衡与能量动态平衡的重要的信号分子 ${ }^{[2]}$, 其主要作 用是控制食欲、体重、能量代谢 ${ }^{[5,6]}$. Dubern等人 ${ }^{[7]}$ 对 
63 位肥胖儿童的 $M C 4 R$ 克隆序列直接测序, 并对 AGRP(agouti-related protein) 和 $\alpha$-MSH 进行 PCRRFLP和PCR-SSCP分析的方法来评测，说明肥胖基 因的表达在个体的突变位点是可变的, 且得出结论 “MC4R 突变可引起儿童肥胖”. 瑞典学者Rosmond等 人 ${ }^{[8]}$ 对人 $M C 4 R$ 的一个错义突变的研究发现, $M C 4 R$ 基 因的错义突变对腹脂分配、Leptin和唾液皮质醇浓度 变化有作用, 提出了 $M C 4 R$ 控制食欲和能量消耗是由 于基因问题使 $M C 4 R$ 失活，从而导致肥胖. Huszar等 人 ${ }^{[9]}$ 用敲除 $M C 4 R$ 基因的方法, 发现小鼠出现多食肥 胖. $\mathrm{Kim}$ 等人 ${ }^{[10]}$ 研究猪的 $M C 4 R$ 基因的错义突变，一个 氨基酸改变编码的错义突变, 发现可引起膘厚、体重 和采食量显著变化.

鸡的 $M C 4 R$ 基因是一个单掿贝基因，仅含有一个 外显子, 其编码序列长度为 $996 \mathrm{bp}$, 编码 332 个氨基 酸，与人和鼠的 $M C 4 R$ 基因有 $86.4 \% \sim 88.1 \%$ 同源性， 在肾上腺、性腺、脾、脂肪和脑等组织表达 ${ }^{[11]}$. 哺乳

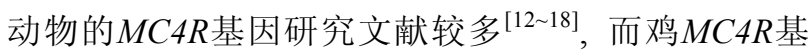
因的主要功能未见有详细的报道. 根据鸡的生长发 育和生理生化特点及 $M C 4 R$ 基因的表达，可以将 $M C 4 R$ 基因作为鸡生长和肉质性状候选基因进行深 入的研究 ${ }^{[19,20]}$. 因此, 利用中国农业大学的鸡的资 源家系做了 $M C 4 R$ 基因的单核苷酸多态(SNPs， single nucleotide polymorphisms), 并对其与鸡生长和 屠体性状进行研究, 为了解 $M C 4 R$ 基因的功能及其对 鸡的分子育种提供理论基础.

\section{1 材料和方法}

\section{1 材料}

（1）实验动物：以明星肉鸡和丝毛乌骨鸡构建资 源家系产生的 $\mathrm{F}_{2}$ 代为实验素材, 其中肉鸡做父本为正 交系，乌骨鸡做父本为反交系，正反交各 4 个家系共 730 只鸡做为实验材料.

(2) 主要试剂、仪器: Taq DNA聚合酶和蛋白酶 $\mathrm{K}$ 购自默克公司 (MERCK Co.); $10 \times \mathrm{PCR}$ 缓冲液 (500 mmol/L KCl, $100 \mathrm{mmol} / \mathrm{L}$ Tris-HCl, $15 \mathrm{mmol} / \mathrm{L}$ $\mathrm{MgCl}_{2}, 1 \%$ 明胶)、dNTPs购自Amersham Pharmacia 公 司; PCR产物回收试剂盒(GeneClean III kit)购自 Qbiogene公司. 还有一些常规试剂购自中国农业大学
供应科. 实验中使用仪器主要包括Gene Amp PCR System 9700(PERKIN ELMER), DYY-III2 稳压电泳 仪 (北京六一仪器厂) 和ABI 377 DNA sequencer (PERKIN ELMER)等.

(3) 引物的设计与合成: 根据 GenBank 中鸡 $\operatorname{MC} 4 R$ (登录号：AB012211)基因的序列，采用 Oligo $\operatorname{primer}(6.0$ 版)软件设计 11 对引物, 引物由上海生工 生物公司合成. 这 11 对引物的序列、位置及其 PCR 产物大小见表 1 .

\section{2 方法}

（1）样品采集和屠体性能测定：资源家系 $F_{2}$ 代 12 周龄时翅静脉采血, 用草酸盐抗凝, $-20^{\circ} \mathrm{C}$ 保存; 之后 屠宰和分割, 称量活体重 $(\mathrm{g})$ 、胸肌重 $(\mathrm{g})$ 、腿肌重 $(\mathrm{g})$ 、 半净膛重 $(\mathrm{g})$ 、全净膛重 $(\mathrm{g})$ 和腹脂重 $(\mathrm{g})$ 等, 并计算出 相应的产率。屠体性能测定的具体方法和步骤按王 启贵等人 ${ }^{[21]}$ 的报道进行.

(2) DNA提取：从冰箱中取出冻血，室温放置至 融化后, 用常规的酚/氯仿抽提制备鸡基因组DNA ${ }^{[22]}$, 然后把DNA样品溶于灭菌水, 浓度在 $100 \mathrm{ng} / \mu \mathrm{L}$, $-20^{\circ} \mathrm{C}$ 冻存备用.

(3) PCR 扩增: PCR 扩增反应体系均为 $25 \mu \mathrm{L}$, 其中 $10 \times \mathrm{PCR}$ 缓冲液 $2.5 \mu \mathrm{L}, \mathrm{dNTPs} 2 \mu \mathrm{L}$, 上游引 物和下游引物各 $25 \mathrm{pmol}, \mathrm{Taq}$ 酶 $1.5 \mathrm{U}$, 模板 DNA 约 $50 \mathrm{ng}$. PCR 反应条件为: 预变性 $94^{\circ} \mathrm{C} 5 \mathrm{~min}$ 后; 进 入如下循环: $94^{\circ} \mathrm{C}, 30 \mathrm{~s}, 56^{\circ} \mathrm{C}, 30 \mathrm{~s}, 72^{\circ} \mathrm{C}, 30 \mathrm{~s} ; 30$ 个循 环后, $72^{\circ} \mathrm{C}$ 延伸 $7 \mathrm{~min}$. PCR 产物在 $2.5 \%$ 琼脂糖凝胶 中电泳，检测 PCR 产物的质量，决定下一步在 SSCP 中的用量.

(4) SSCP 分析和克隆测序: $1 \mu \mathrm{L}$ 的 PCR 产物和 $5 \mu \mathrm{L}$ 的上样缓冲液 ( $98 \%$ 甲酰胺， $0.025 \%$ 澳酚蓝， $0.025 \%$ 二甲苯 FF, $10 \mathrm{mmol} / \mathrm{L} \mathrm{EDTA}(\mathrm{pH} 8.0), 2 \%$ 甘油) 于 $98^{\circ} \mathrm{C}$ 变性 $10 \mathrm{~min}$ 后, 迅速放于冰上; 冰浴 $10 \mathrm{~min}$, 保持变性状态，变性后的 PCR 产物进行非变性聚丙 烯酰胺凝胶(PAGE 30\%, Acr: Bis=29:1)电泳; $10 \mathrm{~V} / \mathrm{cm}$ 电泳 14 16 h 后，银染显色. 对 SSCP 分析后的纯合基 因型个体, 各取 3 个个体的 PCR 扩增产物进行回收纯 化, 经 PCR 扩增产物测序反应后, 在 ABI 377 测序仪 上进行测序. 
表 $1 M C 4 R$ 基因的因物序列

\begin{tabular}{|c|c|c|c|}
\hline 引物名称 & 引物序列 & 位置/bp & PCR 产物大小/bp \\
\hline \multirow[t]{2}{*}{ P1 } & Forward Primer: 5'-AAGCTTGCGCACATCCAAGT-3' & & \\
\hline & Reverse Primer: 5'-GCTGCCGAGCAGAAACTAAT-3' & $-608 \sim-377$ & 232 \\
\hline \multirow[t]{2}{*}{$\mathrm{P} 2$} & Forward Primer: 5'-GCAGCAGTCACTTGAGCATT-3' & & \\
\hline & Reverse Primer: 5'-GCGCTCTCAAAGATGCAGAT-3' & $-380 \sim-180$ & 201 \\
\hline \multirow[t]{2}{*}{ P3 } & Forward Primer: 5'-CTTTGAGAGCGCAAACCAGT-3' & & \\
\hline & Reverse Primer: 5'-TGCTGGGTGAAATTCATCTT-3' & $-191 \sim 18$ & 210 \\
\hline \multirow[t]{2}{*}{ P4 } & Forward Primer: 5'-CTCCAGCCTCTCCATTTCTG-3' & & \\
\hline & Reverse Primer: 5'-GCGAATGGAGGTTCTTGTTC-3' & $28 \sim 229$ & 202 \\
\hline \multirow[t]{2}{*}{ P5 } & Forward Primer: 5'-GCCAAGAACAAGAACCTCCA-3' & & \\
\hline & Reverse Primer: 5'-AATTGATGCAAGCAGGGAAC-3' & 205 408 & 204 \\
\hline \multirow[t]{2}{*}{ P6 } & Forward Primer: 5'-AGTTCCCTGCTTGCATCAAT-3' & & \\
\hline & Reverse Primer: 5'-CAGATGATGACAACGCTGCT-3' & $388 \sim 584$ & 197 \\
\hline \multirow[t]{2}{*}{ P7 } & Forward Primer: 5'-CATTCTCATGGCATCCCTTT-3' & & \\
\hline & Reverse Primer: 5'-GGATTGTAGGGGCAGGAGAT-3' & $612 \sim 821$ & 210 \\
\hline \multirow[t]{2}{*}{ P8 } & Forward Primer: 5'-AGGGGCCATCACTCTCACTA-3' & & \\
\hline & Reverse Primer: 5'-GAGCTCCTGACTCCGAAATG-3' & 723 924 & 202 \\
\hline \multirow[t]{2}{*}{ P9 } & Forward Primer: 5'-GGAGTCAGGAGCTCAGGAAA-3' & & \\
\hline & Reverse Primer: 5'-GGAGGGAAGGGAAAGAGAAA-3' & $911 \sim 1116$ & 206 \\
\hline \multirow[t]{2}{*}{$\mathrm{P} 10$} & Forward Primer: 5'-CCТTCCСТCССАТCTTTGTA-3' & & \\
\hline & Reverse Primer: 5'-TGCACTGTAACTCAGGCAAGTT-3' & $1107 \sim 1337$ & 231 \\
\hline \multirow[t]{2}{*}{ P11 } & Forward Primer: 5'-TGCATATTGGTTGATAATGTTCC-3' & & \\
\hline & Reverse Primer: 5'-CAGGATTGCTGCTGTTTGAG-3' & $1334 \sim 1546$ & 213 \\
\hline
\end{tabular}

（5）MC4R 基因的 5' 调控区潜在的调控元件及蛋 白结合位点的预测: 在网站 http://www.cbrc.jp/research/ db/TFSEARCH.html 上利用 TFSEARCH(1.3 版)软件 进行在线分析.

（6）屠体性状及其与 SNP 的生物统计分析：序 列分析采用 DNAMAN 软件, 之后根据 SSCP 得到 的 SNPs 划分基因型. 将 GenBank 上的鸡 $M C 4 R$ 基 因序列定为野生型基因型，突变个体的基因型为 突变型基因型. 根据所检测群体的数据结构, 利用 SAS(8.2 版)统计软件包的 PROC-GLM 对所发现的突 变位点与鸡的生长和屠体性状进行统计分析. 统计 分析模型: $y=\mu+j+s+r+e$, 其中 $y$ 为生产性能观察值, $\mu$ 为生产性能的最小二乘均值, $j$ 为基因型对生产性能 的效应值, $s$ 为性别对生产性能的效应值, $r$ 为正反交 对生产性能的效应值, $e$ 为随机残差效应.

\section{2 结果}

\subsection{PCR-SSCP 的结果与分析}

本研究设计了 11 对引物, 对资源家系 $\mathrm{F}_{2}$ 鸡群的 $M C 4 R$ 基因共 2224 个碱基全序列进行了 PCR扩增. 通 过对相应的 11 个片段的PCR产物进行SSCP分析，发
现有 3 对引物的PCR产物存在多态. 这 3 对引物分别 是P1, P4 和P5, 其PCR-SSCP结果如下:

利用引物 $\mathrm{P} 1$ 对鸡的 $M C 4 R$ 基因 5'调控区进行 $\mathrm{PCR}$ 扩增，得到了 $232 \mathrm{bp}$ 的目的片段. 对该片段 的 PCR 产物进行 SSCP, 发现存在多态性(图 1(a)), $\mathrm{AA}$ 为野生型基因型, $\mathrm{BB}$ 为突变型基因型, $\mathrm{AB}$ 为杂合 基因型. 引物 P4 的 PCR-SSCP 结果见图 1(b), CC 基 因型为与 GenBank 中的序列(登录号：AB012211) 一 致, $\mathrm{DD}$ 为突变基因型. 同样 $\mathrm{EE}$ 基因型和 $\mathrm{FF}$ 基因型 为引物 P5 的 PCR-SSCP 结果(图 1(c)).

\section{2 多态性片段的克隆和测序结果}

对上述存在SNP的 3 对引物每一种纯合基因型个 体的PCR产物至少进行 3 次测序, 然后将 $\mathrm{F}_{2}$ 鸡群中测 得的含突变位点的序列与 GenBank的 $M C 4 R$ 基因已知 序列(登录号: AB012211)进行同源性比较, 发现共存 在 4 个点突变. 这 4 个点突变的位置、其碱基变化及 其相应的氨基酸变化，以及不同基因型的碱基序列 见表 2. 本文规定 $M C 4 R$ 基因编码区的第 1 个碱基为 +1 , 沿编码区方向顺流而下均用正值表示, 溯流而上 的调控区部分均用负值表示. 由表 2 可知, 第 1 对引 物 P 1 扩增的 P C R 产物中存在多态, 即 -524 

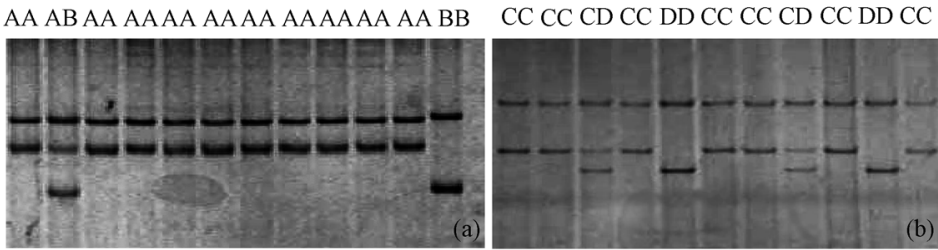

EE EF EE EE FF EF EE EF EE

图 1 不同引物的 $\mathrm{SSCP}$ 电泳图

(a) 引物 P1 的 SSCP 分析; (b) 引物 P4 的 SSCP 分析; (c) 引物 P5 的 SSCP 分析

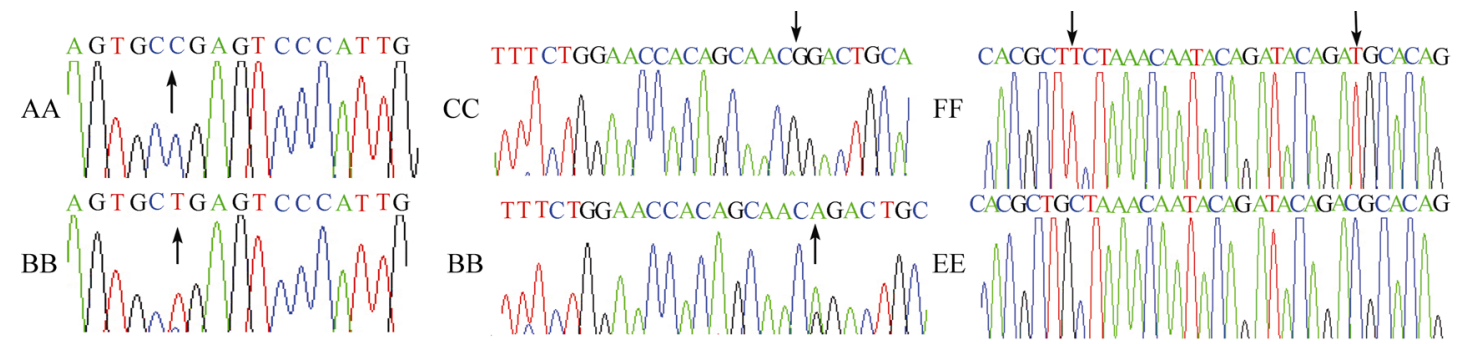

图 2 不同基因型的部分序列测序结果

表 2 不同基因型的序列比对结果

\begin{tabular}{|c|c|c|c|c|}
\hline 基因型 & 碱基序列 $\left(5^{\prime} \rightarrow 3^{\prime}\right)$ & 突变位置 & 碱基变化 & 氨基酸变化 ${ }^{\text {a) }}$ \\
\hline GenBank & ACTTTCTGCA GTGCCGAGTC CCATTGGCTG & & & \\
\hline AA & ACTTTCTGCA GTGCCGAGTC CCATTGGCTG & & & \\
\hline BB & ACTTTCTGCA GTGCTGAGTC CCATTGGCTG & -524 & $\mathrm{C} \rightarrow \mathrm{T}$ & \\
\hline GenBank & TTCTGGAACC AGAGCAACGG ACTGCACAGG & & & \\
\hline $\mathrm{CC}$ & TTCTGGAACC AGAGCAACGG ACTGCACAGG & & & \\
\hline $\mathrm{DD}$ & TTCTGGAACC AGAGCAACAG ACTGCACAGG & 61 & $\mathrm{G} \rightarrow \mathrm{A}$ & G21R \\
\hline GenBank & CTGCTAAACA ATACAGATAC AGACGCACAG & & & \\
\hline EE & CTGCTAAACA ATACAGATAC AGACGCACAG & & & \\
\hline FF & СТTCTAAACA ATACAGATAC AGA $\boldsymbol{T}$ GCACAG & 315,336 & $\mathrm{G} \rightarrow \mathrm{T} ; \mathrm{C} \rightarrow \mathrm{T}$ & L105L; D112D \\
\hline
\end{tabular}

a) G 示甘氨酸(Gly); R 示精氨酸(Arg); L 示亮氨酸(Leu); D 示天冬氨酸(Asp)

位发生了 $\mathrm{C} \rightarrow \mathrm{T}$ 的转换突变; 引物 $\mathrm{P} 4$ 扩增的 $\mathrm{PCR}$ 产 物中存在多态是在 61 位发生了 $\mathrm{G} \rightarrow \mathrm{A}$ 的转换突变, 该 突变为一错义突变，使相应的第 21 位的甘氨酸 $\mathrm{G}(\mathrm{Gly})$ 变为精氨酸 $\mathrm{R}(\mathrm{Arg})$; 第 5 对引物 P5 扩增的 PCR 产物中存在 2 处碱基的改变, 即在第 315 位和第 336 位发生了 $\mathrm{G} \rightarrow \mathrm{T}$ 和 $\mathrm{C} \rightarrow \mathrm{T}$ 的突变, 这两个突变为 同义突变. 不同基因型的部分测序峰图见图 2 .

\subsection{MC4R 基因 5' 调控区潜在的调控元件及蛋 白结合位点的预测分析}

通过网站 http://www.cbrc.jp/research/db/TFSEAR CH.html 上的 TFSEARCH(1.3 版)软件，对鸡 $M C 4 R$ 基 因 $5^{\prime}$ 调控区 $(-608 \sim-1)$ 潜在的调控元件及蛋白结合位 点进行了预测. 结果显示, 突变基因型 $\mathrm{BB}$ 比野生型 的 AA 基因型多了一个 NF-E2 蛋白结合位点和一个 cap 转录因子. $M C 4 R$ 基因 5'调控区上的调控元件及蛋 白结合位点预测结果见表 3 .

\section{$2.4 M C 4 R$ 基因的不同基因型与鸡屠体性状的最 小二乘分析}

本研究采用最小二乘分析方法对 $M C 4 R$ 基因 $5^{\prime}$ 调控区和编码区上的 3 个多态的不同基因型与鸡屠体 性状进行了统计分析.

对资源家系 $\mathrm{F}_{2}$ 代个体的屠体性状与 $M C 4 R$ 5'调控 区的不同基因型进行的的最小二乘分析结果见表 4 . 结果表明，由鸡 $M C 4 R$ 基因 $5^{\prime}$ 调控区的的突变所产 生的 3 种基因型中, BB基因型个体的体重、半净膛重 和腿肉重显著高于 $\mathrm{AA}$ 基因型和 $\mathrm{AB}$ 基因型个体 $(P<0.05)$; 在胸肉重和腹脂重两个性状上, 上述 3 种 基因型个体间的差异不显著 $(P>0.05)$. 
表 3 转录因子与 $M C 4 R$ 基因 $5^{\prime}$ 调控区结合方式的预测结果

\begin{tabular}{ll}
\hline AA 基因型的位点 & BB 基因型的位点 \\
\hline HSF & HSF \\
HSF & HSF \\
HSF & HSF \\
HSF & HSF \\
ADR1 & NF-E2 \\
CCAAT & ADR1 \\
cap & cap \\
GATA-1 & CCAAT \\
NF-1 & cap \\
cap & GATA-1 \\
cap & NF-1 \\
CdxA & cap \\
STRE & cap \\
NF-Y & CdxA \\
cap & STRE \\
& NF-Y \\
& cap \\
\hline
\end{tabular}

资源家系 $\mathrm{F}_{2}$ 代个体的 $M C 4 R$ 引物 $\mathrm{P} 4$ 的不同基因 型与鸡屠体性状的最小二乘分析结果见表 5. DD基 因型个体的体重、半净膛重显著高于 CC 因型个体的 体重、半净膛重 $(P<0.05)$, 并且标准误较大. 而在胸肉 重、腿肉重和腹脂重等 3 个性状上，上述 3 种基因型 个体间的差异不显著 $(P>0.05)$.

同样利用最小二乘分析法对 $M C 4 R$ 基因引物 P5 的不同基因型与鸡屠体性状进行了统计分析. 结果 (见表 6)表明, FF 基因型个体的体重、全净膛重、胸
肉重、腿肉重显著高于 $\mathrm{EE}$ 基因型个体的体重、全净 膛重、胸肉重、腿肉重 $(P<0.05)$, 但在腹脂重上 3 种 基因型个体间的差异不显著 $(P>0.05)$.

\section{3 讨论}

本研究根据哺乳动物 $M C 4 R$ 基因具有控制食欲、 体重、能量代谢和肥胖等功能 ${ }^{[7 \sim 13]}$, 开展鸡 $M C 4 R$ 基 因对生长和屠体性能影响的相关研究. 通过对鸡 $M C 4 R$ 整个基因的PCR-SSCP分析，发现存在 4 个 具有生物学意义的SNPs, 一个是在 $5^{\prime}$ 调控区, 另 3 个是编码区.

$M C 4 R$ 基因的 $5^{\prime}$ 调控区是基因功能调控区. 调 控序列DNA是关于基因选择性表达的信息，可能与 调控蛋白质相互作用而修饰自己的双螺旋空间结构, 以便更好地为调控蛋白质所识别. 本研究检测到的 该基因 $5^{\prime}$ 调控区的 $\mathrm{C} \rightarrow \mathrm{T}$ 的转换突变, 导致此处多 了一个NF-E2 蛋白结合位点和一个转录启始因子 cap 信号. 因此, BB基因型转录因子和蛋白结合位点的 增加及其位置的改变可能会影响 $M C 4 R$ 基因的表达 量 ${ }^{[23,24]}$, 从而使 MC4R 的量有所差异，进而影响生 长和屠体性能. 最小二乘分析证实该基因 5 端调控 区的BB基因型与鸡体重、半净膛重和腿肉重等性状 之间存在显著的相关关系. 然而，有关 $M C 4 R$ 基因的 结构、调控元件的研究很少, 其 $5^{\prime}$ 调控区上碱基的改

表 $4 M C 4 R$ 基因 $5^{\prime}$ 调控区的 $\mathrm{SSCP}$ 多态性与屠体性状最小二乘分析 $(x \pm \mathrm{SD})^{\mathrm{a})}$

\begin{tabular}{ccccccc}
\hline 基因型 & 个体数 & 体重 $/ \mathrm{g}$ & 半净膛重 $/ \mathrm{g}$ & 胸肉重 $/ \mathrm{g}$ & 腿肉重 $/ \mathrm{g}$ & 腹脂重 $/ \mathrm{g}$ \\
\hline $\mathrm{AA}$ & 195 & $1660.16 \pm 27.53^{\mathrm{a}}$ & $1167.62 \pm 21.93^{\mathrm{a}}$ & $93.28 \pm 2.30^{\mathrm{a}}$ & $126.01 \pm 3.06^{\mathrm{a}}$ & $45.14 \pm 2.86^{\mathrm{a}}$ \\
$\mathrm{AB}$ & 50 & $1599.20 \pm 42.08^{\mathrm{a}}$ & $1101.12 \pm 33.53^{\mathrm{a}}$ & $91.91 \pm 3.52^{\mathrm{a}}$ & $122.00 \pm 4.67^{\mathrm{a}}$ & $41.84 \pm 4.37^{\mathrm{a}}$ \\
$\mathrm{BB}$ & 18 & $1777.62 \pm 70.18^{\mathrm{b}}$ & $1269.88 \pm 55.92^{\mathrm{b}}$ & $100.68 \pm 5.86^{\mathrm{a}}$ & $145.28 \pm 7.80^{\mathrm{b}}$ & $49.89 \pm 7.29^{\mathrm{a}}$ \\
\hline
\end{tabular}

a) 字母相同示性状均数差异不显著 $(P>0.05)$, 字母相异示性状均数差异显著 $(P<0.05)$

表 $5 \mathrm{MC} 4 \mathrm{R}$ 基因引物 $\mathrm{P} 4$ 的 $\mathrm{SSCP}$ 多态性与屠体性状最小二乘分析 $(x \pm \mathrm{SD})^{\mathrm{a})}$

\begin{tabular}{ccccccc}
\hline 基因型 & 个体数 & 体重 $/ \mathrm{g}$ & 半净膛重 $/ \mathrm{g}$ & 胸肉重 $/ \mathrm{g}$ & 腿肉重 $/ \mathrm{g}$ & 腹脂重 $/ \mathrm{g}$ \\
\hline $\mathrm{CC}$ & 310 & $1623.49 \pm 21.10^{\mathrm{a}}$ & $1135.29 \pm 16.67^{\mathrm{a}}$ & $91.42 \pm 1.643^{\mathrm{a}}$ & $126.70 \pm 2.07^{\mathrm{a}}$ & $46.58 \pm 2.13^{\mathrm{a}}$ \\
$\mathrm{CD}$ & 260 & $1685.45 \pm 22.39^{\mathrm{b}}$ & $1177.89 \pm 17.69^{\mathrm{b}}$ & $94.09 \pm 1.74^{\mathrm{a}}$ & $129.64 \pm 2.19^{\mathrm{a}}$ & $45.70 \pm 2.26^{\mathrm{a}}$ \\
$\mathrm{DD}$ & 37 & $1717.62 \pm 49.07^{\mathrm{b}}$ & $1213.88 \pm 38.78^{\mathrm{b}}$ & $93.62 \pm 3.82^{\mathrm{a}}$ & $133.16 \pm 4.82^{\mathrm{a}}$ & $41.68 \pm 4.96^{\mathrm{a}}$ \\
\hline
\end{tabular}

a) 字母相同示性状均数差异不显著 $(P>0.05)$, 字母相异示性状均数差异显著 $(P<0.05)$

表 $6 M C 4 R$ 基因引物 $\mathrm{P} 5$ 的 $\mathrm{SSCP}$ 多态性与屠体性状最小二乘分析 $(x \pm \mathrm{SD})^{\mathrm{a})}$

\begin{tabular}{ccccccc}
\hline 基因型数 & 个体 & 体重 $/ \mathrm{g}$ & 半净膛重 $/ \mathrm{g}$ & 胸肉重 $/ \mathrm{g}$ & 腿肉重 $/ \mathrm{g}$ & 腹脂重 $/ \mathrm{g}$ \\
\hline $\mathrm{EE}$ & 101 & $1605.84 \pm 29.30^{\mathrm{a}}$ & $1024.80 \pm 20.85^{\mathrm{a}}$ & $89.68 \pm 2.29^{\mathrm{a}}$ & $124.35 \pm 2.87^{\mathrm{a}}$ & $42.70 \pm 3.03^{\mathrm{a}}$ \\
$\mathrm{EF}$ & 247 & $1665.94 \pm 21.05^{\mathrm{b}}$ & $1061.83 \pm 14.98^{\mathrm{b}}$ & $93.10 \pm 1.64^{\mathrm{b}}$ & $129.18 \pm 2.06^{\mathrm{b}}$ & $47.78 \pm 2.17^{\mathrm{a}}$ \\
$\mathrm{FF}$ & 168 & $1697.45 \pm 26.03^{\mathrm{b}}$ & $1078.83 \pm 18.52^{\mathrm{b}}$ & $96.65 \pm 2.033^{\mathrm{b}}$ & $131.75 \pm 2.55^{\mathrm{b}}$ & $44.78 \pm 2.69^{\mathrm{a}}$ \\
\hline
\end{tabular}

a) 字母相同示性状均数差异不显著 $(P>0.05)$, 字母相异示性状均数差异显著 $(P<0.05)$ 
变对鸡肉用性状产生的作用机理, 目前尚不清楚, 还 有待于进一步研究.

$M C 4 R$ 基因编码区有 3 个突变位点. 一个是引物 $\mathrm{P} 4$ 位于 $\mathrm{MC} 4 \mathrm{R}$ 基因序列的 61 位的核苷酸 $\mathrm{G} \rightarrow \mathrm{A}$ 转换, 这个错义突变 MC4R 蛋白的甘氨酸变为精氨酸. 甘 氨酸属非极性氨基酸, 精氨酸属极性氨基酸, 氨基酸 的变化可能会引起蛋白活性的改变, 进而影响其功 能的发挥. 利用最小二乘对 $M C 4 R$ 基因编码区上的这 个多态所产生的不同基因型与屠体性状的关系进行 的分析, 结果显示 $M C 4 R$ 基因的错义突变对鸡的生长 和屠体等方面有影响. 在性状的表现上，DD 基因型 的体重和半净膛重显著高于 $\mathrm{CD}$ 和 $\mathrm{CC}$ 基因型的个体 的相应性状值 $(P<0.05)$. 另两个是引物 P5 的位于 $M C 4 R$ 基因序列的 315 位点的 $\mathrm{G} \rightarrow \mathrm{T}$ 颠换和位于 336 位点的 $\mathrm{C} \rightarrow \mathrm{T}$ 转换, 这两个 $\mathrm{SNP}$ 没有引起氨基酸的变 化, 为同义突变. 但突变基因型 $\mathrm{FF}$ 个体的体重、全净 膛重、胸肉重、腿肉重显著高于 $\mathrm{EE}$ 基因型个体的 $(P<0.05)$ 相应指标. 这样的数据说明突变影响了鸡的 产肉量, 增加了鸡的体重. 我们对同义突变的作用效 果很感兴趣，但作用机理目前尚不清楚.

综上可知 $M C 4 R$ 基因 $5^{\prime}$ 调控区、编码区上的突变 对鸡的体重、屠体性状有显著影响，但对腹脂没有显 著的影响. 这一结果和大多文献表明哺乳动物 $M C 4 R$ 基因主要影响体重和肥胖 ${ }^{[10 \sim 13]}$ 的结论不十分一致, 但或许证实了 Takeuchi等人 ${ }^{[13]}$ 的结果：即鸡的 $M C 4 R$ 基因在脑、脂肪、肾上腺和生殖腺等组织表达，而哺 乳动物 $M C 4 R$ 仅在脑组织表达, 二者基因表达与调控 存在着较大的差别.

本研究的结果表明, $M C 4 R$ 基因 $5^{\prime}$ 调控区和编码 区的突变是导致鸡生长和屠体表型变异的主要原因, 最小二乘分析也证实了 $M C 4 R$ 基因的多态性与体重、 生长和屠体性状有显著的相关性. 因此, $M C 4 R$ 基因 是影响鸡生长和屠体等性状的主要候选基因，对 $M C 4 R$ 基因的深入研究将为蛋鸡和肉鸡的分子育种 和生产奠定了理论基础.

\section{参考 文 献}

1 Yeo G S, Farooqi I S, Challis B G, Jackon R S, O'Rahilly S. The role of melanocortin signalling in the control of body weight:
Evidence from human and murine genetic models. QJM, 2000, 93(1): 7 14[DOI]

2 Andersson L. Melanocortin receptor variants with phenotypic effects in horse, pig, and chicken. Ann N Y Acad Sci, 2003, 994: $313 \sim 318$

3 Xu B, Goulding E H, Zang K, Cepoi D, Cone R D, Jones K R, Tecott L H, Reichardt L F. Brain-derived neurotrophic factor regulates energy balance downstream of melanocortin-4 receptor. Nat Neurosci, 2003, 6(7): 736 742[DOI]

4 Sinha P S, Schioth H B, Tatro J B. Roles of the melanocortin-4 receptor in antipyretic and hyperthermic actions of centrally administered alpha-MSH. Brain Res, 2004, 1001(1 2): 150 158[DOI]

5 Hoggard N, Hunter L, Duncan J S, Rayner D V. Regulation of adipose tissue leptin secretion by alpha-melanocyte-stimulating hormone and agouti-related protein: Further evidence of an interaction between leptin and the melanocortin signalling system. J Mol Endocrinol, 2004, 32(1): 145 153[DOI]

6 Costa J L, Brennen M B, Hochgeschwender U. The human genetics of eating disorders lessons from the leptin/melanocortin system. Child Adolesc Psychiatr Clin N Am, 2002, 11(2): 387 397[DOI]

7 Dubern B, Clement K, Pelloux V, Froguel P, Girardet J P, Guy-Grand B, Tounian P. Mutational analysis of melanocortin-4 receptor, agouti-related protein, and alpha-melanocyte- stimulating hormone genes in severely obese children. J Pediatr, 2001, 139(2): 204 209[DOI]

8 Rosmond R, Chagnon M, Bouchard C, Bjorntorp P. A missense mutation in the human melanocortin-4 receptor gene in relation to abdominal obesity and salivary cortisol. Diabetologia, 2001, 44 (10): 1335 1338[DOI]

9 Huszar D, Lynch C A, Fairchild-Huntress V. Targeted disruption of the melanocortin-4-reeptor results in obesity in mice. Cell, 1997, 88(1):131 141[DOI]

10 Kim K S, Larsen N, Short T, Plastow G, Rothschild M F. A missense variant of the porcine melanocortin-4 receptor (MC4R) gene is associated with fatness, growth, and feed intake traits. Mammalian genome, 2000, 11(2): 131 135[DOI]

11 Takeuchi S, Takahashi S. Melanocortin receptor genes in the chicken-Tissue distributions. Gen Comp Endocrinol, 1998, 112(2): 220 231[DOI]

12 Srinivasan S, Lubrano-Berthelier C, Govaerts C, Picard F, Santiago P, Conklin B R, Vaisse C. Constitutive activity of the melanocortin-4 receptor is maintained by its $\mathrm{N}$-terminal domain and plays a role in energy homeostasis in humans. J Clin Invest, 2004, 114(8): 1158 1164 [DOI]

13 Ma L, Tataranni P A, Bogardus C, Baier L J. Melanocortin 4 re- 
ceptor gene variation is associated with severe obesity in Pima Indians. Diabetes, 2004, 53(10): 2696 2699

14 Lubrano-Berthelier C, Le Stunff C, Bougneres P, Vaisse C. A homozygous null mutation delineates the role of the melanocortin- 4 receptor in humans. J Clin Endocrinol Metab, 2004, 89(5): 2028 2032[DOI]

15 Starowicz K, Bilecki W, Sieja A, Przewlocka B, Przewlocki R. Melanocortin 4 receptor is expressed in the dorsal root ganglions and down-regulated in neuropathic rats. Neurosci Lett, 2004, 358(2): 79 82 [DOI]

16 Valli-Jaakola K, Lipsanen-Nyman M, Oksanen L, Hollenberg A N, Kontula K, Bjorbaek C, Schalin-Jantti C. Identification and characterization of melanocortin-4 receptor gene mutations in morbidly obese finnish children and adults. J Clin Endocrinol Metab, 2004, 89(2): 940 945 [DOI]

17 Valle E, Habermann F A, Moore S S, Crews D H, Benkel B F. Genomic localization and SNP discovery in the bovine melanocortin receptor 4 gene (MC4R). Anim Genet, 2004, 35(4): 351 352[DOI]

18 Houston R D, Cameron N D, Rance K A. A melanocortin-4 re- ceptor (MC4R) polymorphism is associated with performance traits in divergently selected Large White pig populations. Anim Genet, 2004, 35(5): 386 390 [DOI]

19 仇雪梅, 李 宁, 邓学梅, 吴常信. 影响动物肉质性状主要候 选基因的研究进展. 遗传, 2002, 24(5): 571 574

20 仇雪梅, 李 宁, 吴常信, 王秀利. 用放射杂交板定位鸡的 MC4R 基因及其在鸡和人染色体上同源区的比较分析.遗传学 报, 2004, 31(12): 1356 1360

21 王启贵, 李 宁, 邓学梅, 连正兴, 李 辉, 吴常信. 鸡细胞外 脂肪酸结合蛋白基因单核甘酸多态性与腹脂性状关系的研 究. 中国科学, C 辑, 2001, 31(3): 266 270

22 Sambrook J, Fritsch E F, Maniatis T, Molecular Cloning: A Laboratory Manual. 2nd. New York: Cold Spring Harbor Laboratory Press, 1989

23 Doevendans P A, van Bilsen M. Transcription factors and the cardiac gene programme. Int J Biochem Cell Biol, 1996, 28(4): 387 403[DOI]

24 Cormier P, Pyronnet S, Salaun P, Mulner-Lorillon O, Sonenberg N. Cap-dependent translation and control of the cell cycle. Prog Cell Cycle Res, 2003, 5: 469 475 